\title{
PEMBELAJARAN SEPANJANG HAYAT MENUJU MASYARAKAT BERPENGETAHUAN
}

\author{
Esi Hairani \\ Dosen Tetap Fakultas Tarbiyah Institut Ilmu al-Qur'an (IIQ) Jakarta \\ esihairani@yahoo.co.id
}

\begin{abstract}
Abstrak
Indonesia, hingga saat ini, belum memiliki payung hukum secara khusus mengatur belajar sepanjang hayat. Dalam Undang-undang Nomor 20 Tahun 2003 tentang Sistem Pendidikan Nasional sekalipun, istilah pendidikan atau belajar sepanjang hayat baru menjadi bagian kecil saja dari kebijakan makro pendidikan di Indonesia. "Setiap warga Negara berhak mendapat kesempatan meningkatkan pendidikan sepanjang hayat". ${ }^{1}$ Apa yang tersirat dalam Undangundang Nomor 20 Tahun 2003 tentang Sistem Pendidikan Nasional di atas, belum cukup dipandang sebagai dasar kebijakan yang komprehensif tentang penyelenggaraan belajar sepanjang hayat di Indonesia. Padahal penjabaran konsep dan prinsip belajar sepanjang hayat ke dalam pemahaman yang lebih operasional mutlak diperlukan. Terutama dalam menyiapkan program-program altrernatif secara kreatif dan inovatif yang mampu memecahkan persoalan-persoalan di atas tadi, khususnya program yang memiliki substansi lingkungan, kecakapan hidup dan lapangan kerja, dan kependudukan. Masyarakat berpengetahuan ditopang oleh empat pilar, yaitu (1) system pendidikan, yang menjamin masyarakat dapat memanfaatkan ilmu pengetahuan secara luas; (2) system inovasi, yang mampu membawa peneliti dan kalangan bisnis menerapkan secara efektif terhadap informasi dan komunikasi; dan (4) kerangka kelembagaan dan ekonomi, terjaminnya kemantapan lingkungan makro ekonomi, persaingan, lapangan kerja buruh dan keamanan sosial. Belajar sepanjang hayat dapat dijabarkan secara kontinum ke dalam program-program pendidikan di tingkat satuan penidikan pada jalur formal, nonformal, dan informal. Karena belajar merupakan suatu proses sepanjang hayat yang mencakup keseluruhan kurung waktu hidup seorang individu yang mengarah pada upaya untuk menumpang masyarakat belajar (learning society).
\end{abstract}

Kata Kunci: Longlife Education, Knowledge Society

\section{Pendahuluan}

Konsep belajar sepanjang hayat pertama kali dikemukakan oleh Edgar Faure dari International Council og Educational Development (ICED) atau Komisi Internasional Pembangunan Pendidikan. sebagai Ketua Komisi tersebut, Edgar Faure menegaskan bahwa istilah belajar terinspirasi oleh sebuah ungkapan hikmah yang diungkapkan oleh ulama Islam yang berbunyi "uthlubul 'ilma minal mahdi ilal lahdi", yang bermakna "tuntutlah ilmu dari sejak dalam kandungan (buaian) hingga liang lahat". Penegasan Faure tersebut kemudian digambarkan dalam pernyataanya bahwa: Withd its Confidendce in man's capacity to perpect himself through education, the Moslem world was among the first to recommend the idea of lifelong education, exhorting Moslem to educate themselves from cradle to the grave. 
Agama Islam adalah agama yang sangat mementingkan pembelajaran. Dalam sejarah Islam, Nabi Muhammad tidak pernah disuruh memintah tambahan apapun kecuali tambahan ilmu, hal ini termaktub dalam QS T\{a>ha>/20: 114.

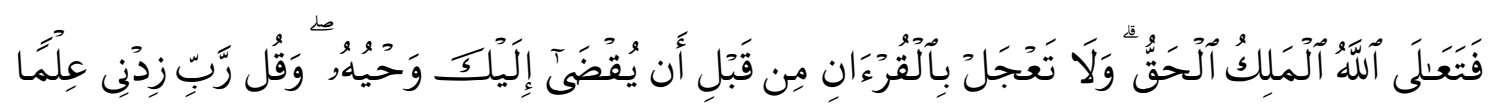

Terjemahnya:

Maka Maha Tinggi Allah raja yang sebenar-benarnya, dan janganlah kamu tergesagesa membaca al-Qur'an sebelum disempurnakan mewahyukannya kepadamu, dan Katakanlah: "Ya Tuhanku, tambahkanlah kepadaku ilmu pengetahuan."2

Selain itu, Ibn Ma>jah dalam sunannya juga meriwayatkan sebuah hadis yang berisi doa yang semakna dengan ayat diatas sebagai berikut:

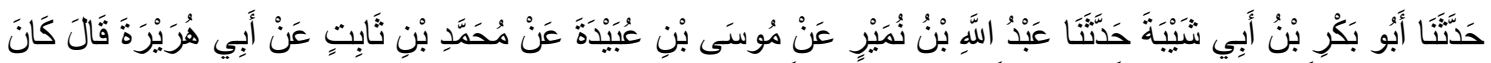

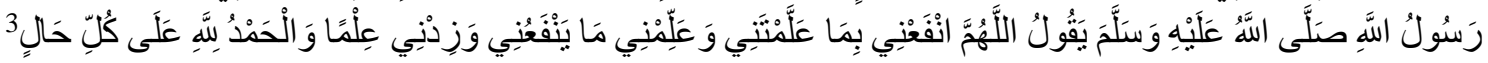
Artinya:

Telah menceritakan kepada kami Abu> Bakr bin Abi> Syaibah telah menceritakan kepada kami 'Abdullah bin Numair dari $\mathrm{Mu}>\mathrm{sa}>$ bin 'Ubaidah dari Muh\}ammad bin $\mathrm{S} \mid \mathrm{a}>$ bit dari Abi> Hurairah di berkata, bahwa Rasulullah saw. bersabda: Ya Allah berikanlah manafaat atas apa yang Engkau ajarkan kepadaku dan ajarkanlah apa yang bermanfaat bagiku, tambahkanlah ilmuku dan segala puji bagi Allah di setiap keadaan.

Proses belajar sepanjang hayat yang sering pula dikenal dengan proses pendidikan sepanjang hayat, nampaknya menjadi kecenderungan (trends) pilihan di berbagai Negara, seperti Jepang, Thailand, India, beberapa Negara di Afrika, dan Negara-negara yang tergabung dalam Uni Eropa. Di Jepang misalnya telah diterbitkan regulasi sebagai wujud komitmen bersama dalam bentuk Undang-undang Belajar Sepanjang Hayat (the law for the Promotion Of Lifelong Learning). Bahkan Negara-negara yang tergabung dalam Uni Eropa memiliki komisi khusus yang menangani proses belajar sepanjang hayat, termasuk pengembangan indikator dan system penjaminan mutunya.

Masyarakat Indonesia tengah hidup dan mulai masuk kedalam sebuah ekonomi pengetahuan (knowledge economy) dan sebuah masyarakat berpengetahuan (knowledge society). Ekonomi pengetahuan bertumbuh karena adanya kreativitas dan kemampuan mencipta yang memungkinkan pemecahan masalah secara cerdas (ingenuity). Satuansatuan pendidikan pada jalur pendidikan formal, nonformal, dan informal dalam

${ }^{2}$ Kementerian Agama RI, Syaamil al-Qur'an Terjemah Tafsir Per Kata (Bandung: PT. Sygma Examedia Arkaleema, 2014), 320. t.th), h, 293.

${ }^{3} \mathrm{Ibn} \mathrm{Ma}>\mathrm{jah} \mathrm{Abu}>$ 'Abdillah Muh\}ammad bin Yazi>>d al-Quzwaini>, Sunan Ibn Ma>jah, Juz I (Mauqi' al-Islam: t.tp, 
masyarakat berpengetahuan harus menciptakan kualitas ini; kalau tidak, masyarakat dan bangsa akan ditinggalkan. ${ }^{4}$

Abad 21 ini, menurut Drucker adalah abad transformasi sosial dengan kecenderungan: (a) Terjadi perubahan struktur sosial dan transformasinya, misalnya kebangkitan dari pekerja kerah biru (blue color) menuju kebangkitan pekerja. (b) Munculnya masyarakat berpengetahuan dengan cirri bekerja dalam organisasi dan jaringan-jaringan masyarakat karyawan yang luas, dan relative makin berkurangnya pekerjaan tetap seumur hidup. (c) Masyarakat berpengetahuan yang terdiri dari tiga sektor yakni: sektor public (pemerintah), sektor swasta (bisnis) dan sektor sosial (stake holders dan lainnya). ${ }^{5}$

Kawasan (scope) penelitian meliputi kajian konseptual teoritik, analisis kebijakan (policy analysis) belajar sepanjang hayat, khususnya yang terkait dengan peningkatan mutu dan program belajar sepanjang hayat, direlevansikan dengan kajian empiric pada satuan dan penyelenggaraan program pendidikan secara keseluruhan.

Mengingat penjabaran program belajar sepanjang hayat secara kontinum ke dalam program pendidikan di tingkat satuan pendidikan formal, nonformal, dan informal spektrumnya terlalu luas, maka ruang kajian penelitian ini dibatasi pada programprogram belajar sepanjang hayat yang di implementasikan dalam jalur pendidikan nonformal, yang dipandang paling responsive terhadap asas dan prinsip belajar sepanjang hayat. Artinya, penelitian ini di fokuskan pada program belajar sepanjang hayat yang diselenggarakan pada jalur dan lingkup satuan pendidikan nonformal.

Pendidikan nonformal acapkali dihubungkan dengan pendidikan atau belajar sepanjang hayat karena menawarkan program-program yang diikuti sampai tua, dan dibutuhkan sepanjang orang masih hidup ${ }^{6}$. Program-programnya beraneka ragam mengikuti keanekaragaman kebutuhan masyarakat.

Dalam perspektif penulis, pendapat Rogers mampu memperkuat argumentasi berikutnya mengenai pemilihan program dan pendidikan nonformal sebagai fokus penelitian. Mengutip beberapa hasil konvensi sebelumnya di tingkat internasional, Rogers mengemukakan dua hal penting sebagai berikut: (1) mengakui bahwa system pendidkan formal tidak mampu merespon berbagai tantangan yang muncul seiring dengan dinamika perkembangan yang demikian cepat. Dan ketidakmampuan pendidikan formal tersebut dapat diatasi dan diperkuat dengan praktek-praktek pendidikan nonformal; (2) merekomendasikan bahwa pemerintah dan pemegang otoritas kebijakan pendidikan dan semua Negara di dunia untuk mengakui pendidikan nonformal sebagai mitra de facto dalam proses belajar sepanjang hayat dan membuatnya mampu diakses oleh semua. ${ }^{7}$

\footnotetext{
${ }^{4}$ Andy Hargreaves, Teaching in the Knowledge Society: Education in the Age of Insecurity (New York and London: Columbia University, 2003), 10.

${ }^{5}$ Peter F. Drucker, Manajemen di Tengah Perubahan (Jakarta: Gramedia, 2007), 201.

${ }^{6}$ Ali A. Abdi and Dip. Kapoor, Global Perspektif on Adult Education (New York: Palgrave MacMilan, 2009), 2.

${ }^{7}$ Alan Rogers, Non-Formal Education: Fleksibel Schooling or Participatory Education? (New York: Springger Science Bussines Medis Inc, 2005), 228.
} 


\section{Konsep Masyarakat Berpengetahuan}

Pada tahun 1995 Komisi Eropa yang memublikasikan semacam 'buku putih”, yang berjudul "Teaching and Learning Society", yang bertujuan untuk membantu Eropa bergerak menuju masyarakat berbasis pengetahuan (knowledge based society) sebagai tahapan penting di dalam mewujudkan kemajuan sosial dan ekonomi. Dalam buku tersebut juga diungkapkan tiga faktor yang bisa mengakibatkan ketidakstabiln masyarakat, yaitu: adanya dampak masyarakat informasi, dampak industrialisasi, dan dampak perkem-bangan IPTEK dunia.

Menghadapi situasi sebagaimana digambarkan di atas, diperlukan suatu proses yang mampu mengembangkan potensi manusia secara keseluruhan. Proses tersebut adalah belajar. Belajar merupakan kunci untuk memperoleh kemakmuran-baik kemakmuran individu, masyarakat atau suatu bangsa secara keseluruhan, investasi dalam bentuk "'human capital" akan menjadi keberhasilan dan ekonomi global yang berbasis pengetahuan pada abad 21 ini. Belajar dalam suatu masyarakat merupakan hal yang sangat penting, untuk membantu meningkatkan, mendorong regenerasi ekonomi dan kesejahteraan individu, membangun warga Negara yang aktif, dan menginspirasikan dalam keswadayaan. Oleh karena itu, dalam konteks ini pemerintah harus menempatkan belajar sebagai 'the heart of its ambition'.

Dua konsep yang secara lansung terkait dengan belajar sepanjang hayat adalah konsep masyarakat informasi dan mayarakat berpengetahuan. Kedua konsep ini keberadaanya sangat penting sebagai instrument untuk memahami belajar sepanjang hayat dan masyarakat belajar. ${ }^{8}$

Masyarakat informasi merujuk pada suatu masyarakat yang memanfaatkan pengetahuan sebagai sumber utama dalam meningkatkan produksi komoditas informas, sangat dibutuhkan untuk mempersiapkan tenaga-tenaga produktif yang mampu kompetitif di berbagai belahan dunia. ${ }^{9}$

UNESCO secara jelas membedakan antara masyarakat informasi dengan masyarakat berpengetahuan. ${ }^{10}$ Menurut UNESCO, teknologi komunikasi dan informasi baru telah menciptakan kondisi-kondisi baru bagi munculnya masyarakat berpengetahuan. Kemunculan masyarakat informasu global dapat membawa kea rah pencapaian tujuan yang lebih tinggi dan lebih diinginkan, yakni pembangunan pada skala global. Dengan kata lain, masyarakat berpengetahuan merupakan sumber dari pembangunan untuk semua.

Komisi Eropa telah mengidentifikasi beberapa teknologi informasi yang dapat digunakan untuj tujuan-tujuan pendidikan, baik dalam konteks bisnis/komersil maupun di dalam belajar masyarakat.

${ }^{8}$ Peter Jarvis, Globalication, Live Long Learning and the Learning Society: Sociological Perspektif (London and New York: Routledge, 2007), 77.

${ }^{9}$ J.F Lyoratrd, The Post Modern Condition: a Report on Knowledge Manchester (Manchester University Press, 2004), 5.

${ }^{10}$ UNESCO, to Wards Knowledge Societies (Paris: UNESCO, 2005), 27. 
Diyakini betul bahwa teknologi komunikasi dan informasi dapat menjadi alat untuk memberdayakan peserta didik di dalam beragam aktivitas yang menyenangkan dan demokratis.

Terdapat beberapa dasar pemikiran tentang isu masyarakat berpengatahuan adalah (a) pada masa ekonomi modern, sumber daya yang paling fundamental adalah pengetahuan, oleh karena itu proses yang paling penting dalam pembangunan ekonomi adalah proses belajar; (b) belajar merupakan proses yang interaktif. Karena itu situasi sosial mewujudkan proses belajar; (c) menciptakan kondisi kea rah keberhasilan "Mayarakat Berpengetahuan" adalah perhatian utama bagi dan umtuk upaya empowerment of people atau pemberdayaan masyarakat; (d) pentingnya pemanfaatan ICT sebagai media untuk menciptakan masyarakat berpengetahuan; (e) ICT memiliki potensi yang sangat besar, terutama untuk Negara-negara bekembang, dan dalam upaya pembangunan berkelanjutan; (f) walaupun biaya cukup tinggi dalam membangun infrastuktur system informasi nasional, namun biaya yang diakibatkan ketika tidak mengupayakannya bisa menjadi lebih tinggi.

Pengertian knowledge Bassed Society mulai muncul ketika lahirnya kesadaran tentang peran penting ilmu pengetahuan dan teknologi dalam pertumbuhan ekonomi. "Knowledge" yang menyatu (embodied) dengan sumber daya manusia sebagai 'human capital" dan teknologi menjadi pusat pembangunan ekonomi. ${ }^{11}$ Teknologi yang terus mengalami perubahan bersamaan dengan proses globalisasi, bergerak menuju transformasi ekonomi yang dikenal dengan Knowledge Based Society. ini merupakan tahapan lebih lanjut dari pembangunan ekonomi berbasis sumber daya alam menuju pembangunan berbasis ilmu pengetahuan. Di dalamnya, sumber daya manusia sebagai akibat pendidikan tumbuh menjadi faktor yang menentukan dalam kebijakan public untuk meningkatkan kesejahteraan dan kualitas kehidupan suatu Negara.

Ada empat pilar yang menopang masyarakat berbasis pengetahuan, yaitu (1) Sistem Pendidikan, yang menjamin masyarakat dapat memanfaatkan ilmu pengetahuan secara luas; (2) Sistem Inovasi, yang mampu membawa peneliti dan kalangan bisnis menerapkan secara komersial hasil riset dan teknologi; (3) infrastruktur masyarakat Informasi, menjamin masyarakat dapat melakukan akses secara efektif terhadap informasi dan komunikasi; (4) kerangka Kelembagaan dan Ekonomi, terjaminnya kemantapan lingkungan makroekonomi, persaingan, lapangan kerja buruh dan keamanan sosial.

Menurut Drucker knowledge society adalah sebuah masyarakat dari berbagai organisasi dimana secara praktis setiap tugas tunggal akan dilakukan dalam dan melalui sebuah organisasi. ${ }^{12}$ Ciri-ciri masyarakat berpengatahuan adalah:

1. Memiliki kemampuan akademik

2. Berpikir kritis

3. Berorientasi kepada pemecahan masalah

${ }^{11}$ B. Setiadi, Membangun Indonesia Knowledge Based Society (Jakarta: Kementerian Riset Teknologi Bidang Program Ilmu Pengetahuan dan Teknologi, 2007), 2.

${ }^{12}$ Peter F. Drucker, Knowledge Work and Knowledge Society: the Social Transformation of this Century, 2. 
4. Mempunyai kemampuan untuk belajar meningalkan pemikiran yang lamalama dan belajar lagi untuk hal-hal yang baru

5. Mempunyai keterampilan pengembangan individu dan sosial (termasuk kepercayaan diri, motivasi, komitmen terhadap nilai-nilai moral dan etika, pengertian secara luas akan masyarakat dan dunia.

Proses pendidikan menjadi pusat dari masyarakat berpengetahuan dan lembaga atau satuan pendidikan merupakan institusi kuncinya. Pernyataan itu diperkuat bahwa untuk bisa kompetitif dalam ekonomi berpengetahuan global (global knowledge economy), semua pengambil keputusan untuk public harus focus pada pendidikan sebagai faktor kunci dalam memperkuat daya saing, lapangan kerja dan keterpaduan sosial. Drucker memperkuat kesimpulan itu dengan menyatakan bahwa pekerja berpengetahuan lebih mempunyai kesempatan memperoleh akses terhadap pekerjaan dan posisi sosial melalui pendidikan formal. ${ }^{13}$ Tujuan utama dari pendidikan adalah untuk memberikan kepada setiap orang kesempatan untuk mengembangkan potensi dirinya sampai maksimun, baik sebagai individu maupun sebagai seorang anggota masyarakat. Transformasi dari struktur masyarakat yang ada, dengan pengetahuan sebagai sumber daya utama untuk pertumbuhan ekonomi, lapangan pekerjaan dan sebagai faktor dari produksi, merupakan basis untuk menandai masyarakat modern yang maju sebagai sebuah masyarakat berpengetahuan.

Negara berbasis pengetahuan adalah Negara yang salah satu kemakmurannya dihasilkan melalui aktivitas intelektual dari warganya yang mereka peroleh dari pendidikan yang benar sehingga secara realtif warga tersebut mempunyai keunggulan di atas rata-rata warga Negara bangsa lain pada umumnya.

Menurut Gani ada tiga sasaran atau tujuan dari paradigma knowledge society di Indonesia. ${ }^{14}$ Pertama, untuk menyediakan akses pendidikan yang seluas-luas kepada seluruh masyarakat (to provide adequate and equitable access to education for all citizens) yang pada muaranya akan mendorong peningkatan angka partispasi belajar masyarakat di semua jenjang pendidikan. Kedua, untuk meningkatkan kualitas, daya kompetisi dan relevansi pendidikan (to inprove quality competitiveness, and relevance of education) bagi setiap insan Indonesia di percaturan nasional maupun internasional. Ketiga, untuk meningkatkan tata kelola pendidikan (to improve govermance in education) yang akuntabel, baik secara administratif maupun edukatif.

Pembangunan masyarakat berpengatahuan di Indonesia bukan saja menjadi komitmen Depdinas, namun telah menjadi komitmen semua departemen dan lembaga pemerintah yang bersentuhan lansung kepada kesejahteraan rakyat termasuk juga sekolah negeri yang dibiayai oleh depdiknas. Dengan kolaborasi antar berbagai lembaga, maka diharapkan proses pencerdasan masyarakat yang: melek dan cakap memanfaatkan teknologi infomasi dan komunikasi serta media (ICT and Media literacy skills), cakap

\footnotetext{
${ }^{13}$ Peter F. Drucker, Knowledge Work and Knowledge Society: the Social Transformation of this Century (http://www.knowledge.org, 2004), 3.

${ }^{14}$ Lilik Gani, Belajar dengan Teknologi Menunju Masyarakat Berpengetahuan, Makalah Kongres VI dan Seminar Nasional Ikatan Profesi Pendidikan Teknologi Pendidikan (IPTPI).
} 
berpikir kritis (critical thinking skills), cakap memecahkan permasalahan (problemsolving skills), cakap berkomunikasi secara efektif (effective communications skills), dan cakap bekerja-sama secara kolaboratif (collaborative skills) dapat segera terwujud merata di seluruh nusantara.

\section{Konsep dan Teori Belajar Sepanjang Hayat}

Ide pendidikan sepanjang hayat (lifelong education) pertama kali dicetuskan oleh komisi internasional untuk Pembangunan Pendidikan ICDE, suatu badan internasioal di bawah UNESCO. Kegiatan pendidikan sepanjang hayat sesungguhnya merupakan fenomena alamiah dalam kehidupan manusia. ${ }^{15}$ Muncul dan berkembangnya kegiatan pendidikan sepanjang hayat ini, pada dasarnya memenuhi kebutuhan belajar (learning needs) dan kebutuhan pendidikan (ducational needs) yang berkembang secara berkelanjutan dalam sejarah kehidupan manusia. Misi pendidikan sepanjang hayat pada dasarnya adalah membentuk masyarakat belajar (learning society) dan masyarakat berencana (planning society).

Dalam perkembangannya, gagasan pendidikan sepanjang hayat telah sejak lama dilontarkan oleh para ahli ${ }^{16}$, diantaranya:

1. Ditemukan dalam tulisan Mattew Arneld, yang melukiskan tentang konseptualisasi pendidikan sebagai alat untuk pengembangan diri setiap individu yang akan belajar sepanjang hayat agar menjadi bernilai bagi masyarakatnya.

2. Joh Dewey, mengemukakan pandangannya lebih dari 80 tahun lalu bahwa pendidikan dan belajar adalah proses sepanjang hayat.

3. Laporan terhadap pemerintah inggris pada akhir perang dunia pertama, oleh Kementerian Komite Rekonstruksi Pendidikan Orang Dewasa tahun 1919, secara khusus memberikan rekomendasi bahwa pendidikan harus sepanjang hayat, sebagai persoalan penting Nasional.

4. Demikian pula secara aplikatif fenomena di lapangan, pendidikan sepanjang hayat sesungguhnya telah sejak lama dilaksanakan oleh setiap individu ataupun masyarakat, bahwa lembaga keagamaan telah mengenal sistem pendidikan semacam ini, aeperti sistem pndok di Malaysia, pondok pesantren di Indonesia, sekolah minggu di negara-negara Eropa dan Amerika Serikat. Sistem magang dalam berbagai bentuk dilaksanakan baik oleh lingkungan keluarga untuk mempelajari keterampilan-keterampilan tertentu, ataupun oleh sanggar-sanggar kerajinan rakyat, pabrik bengkel kerja, dan sebagainya, yang semuanya melibatkan orang dewasa belajar. ${ }^{17}$

${ }^{15}$ H. Djudju Sudjana, Pendidikan Non Formal: Wawasan, Sejarah, Perkembangan, Filsafat, Teori Pendukung, Asas (Bandung, Falah Pruduction, 2004), 225.

${ }^{16}$ Peter Jarvis, The Age of Learning: Education and Knowledge Society (London: Kogan Page, 2001), 64.

${ }^{17}$ UNESCO, Global Report on Adults Learning ang Education (Hamburg: UNESCO Institut for Lifelong Learning, 2009, 23. 
Gagasan atau fenomena lapangan tentang pendidikan sepanjang hayat di atas semula masih merupakan sesuatu yang belu m begitu dipahami dan dikenal secara meluas. Melalui satu lembaga di bawah UNESCO yaitu international Comission on the Development of Education (ICDE), berupa tulisan sebagai laporan yang dipublikasikan, berjudul: Learning To Be: The World of Education Today and Tomorrow. Laporan tersebut ditulis Edgare Faure dkk, dan terkenal dengan istilah laporan Faure. Adapun isi laporan tersebut memuat rekomendasi pertama untuk perencana-perencana pendidikan. Rekomendasi tersebut dalam bentuk proposal yang disebut pendidikan sepanjang hayat akan diadptasikan sebagai master concept untuk inovasi pendidikan di masa mendatang. Rekomendasi ditujukan kepada negara maju dan juga negara sedang berkembang.

Diskurs tentang belajar sepanjang hayat dalam konteks kekinian, erat kaitannya dengan perubahan teknologi, ekonomi dan posisi negara. Di masa mendatang dengan perubahan teknologi informasi yang begitu peat masyarakat memilki akses dan kesempatan yang luas untuk belajar sepanjang hayat. Kapan saja dan dimana saja, serta siapa saja dapat melakukan proses belajar tersebut. Masyarakat menjadi masyarakat belajar dan berpengetahuan. ${ }^{18}$

Belajar sepanjang hayat, masyarakat belajar dan masyarakat berpengetahuan memiliki makna dan spektrum yang luas. ${ }^{19}$ Di skandinavia, terutama di Swedia, belajar sepanjang hayat digunakan untuk reformasi seluruh teori pendidikan sekolah dan sangat sukses mengembangkan mekanisme belajar sepanjang hayat. Belajar sepanjang hayat yang dikembangkan di Swedia juga mampu memnuhi kebutuhan dan tuntutan perubahan masyarakat sekaligus menjawab ketidakmampuan lembaga pendidikan formal memenuhi harapan masyarakat, sebagai akibat atau akses berkembangnya paham de-schooling . Yakni suatu pandangan yang menganggap sekolah sebagai biang kegagalan membangun dan mengembangkan potensi individu, akibat kekakuan dan keterkungkungan individu selama mengikuti praktek pendidikan di sekolah.

Disamping dalam beberapa tulisan yang lain, seperti dibahas oleh Aspin dan Chapman $^{20}$, terminologi teori belajar sepanjang hayat (theory of lifelong learning) juga dideskripsikan oleh Jarvis dalam volume 2 dari trilogi tulisannya tentang globalisasi, belajar sepanjang hayat dan masyarakat belajar. Menurut Jarvis, belajar sepanjang hayat merupakan kombinasi proses dalam keseluruhan hidup seseorang-baik jasmani (genetik, fisik, dan biologis) dan pikiran (pengetahuan, kecakapan, sikap, nilai, emosi keyakinan, dan perasaan)-situasi pengalaman sosial, ide/gagasan yang kemudian ditransformasikann secara kognitif, afektif, dan praktek (atau melalui beberapa kombinasi transformasi), dan diintegrasikan kedalam biografi kehidupan seseorang yang mengahsilkan perubahan atau pengalaman secara berkelanjutan. ${ }^{21}$

\footnotetext{
${ }^{18}$ J. Michael Hatton, Lifelong Learning: Policies, Practice and Programs (Toronto: School of Media Studies at Hamburg College, 2007), 360.

${ }^{19}$ Peter Jarvis, The Age of Learning: Education and Knowledge Society, 65.

${ }^{20}$ David N Aspin and Judith D Chapman (ed), Values Education and Lifelong Learning: Principles, Polices, Programmes. Dordrecht, the Netherlands: Springer, 2007, 87.

${ }^{21}$ Peter Jarvis, Globalication, Live Long Learning and the Learning Society: Sociological Perspektif, 1.
} 
Teori belajar sepanjang hayat distimulasi oleh pikiran-pikiran dari teori belajar manusia (theory of human learning), yang mengakui adanya the lifelong nature dalam suatu aktivitas belajar seseorang. Penting dicatat, bahwa belajar merupakan proses interaksi dan relasi yang berlansung sepanjang hidup seseorang dalam suatu konteks sosial tertentu, hingga berakhir dengan kematian. ${ }^{22}$ Artinya bahwa, belajar merupakan suatu proses transformasi pengalaman yang dimiliki seseorang dan akan selalu terjadi ketika individu berinteraksi dengan lingkungan sosial yang lebihl luas. Pengalaman tersebut dimulai dari sensasi tubuh (body sensation), seperti suara, cahaya, bebauan, dan lain-lain. Selanjunya seseorang dapat mentransformasikan sensasi tersebut dan belajar membuatnya bermakna bagi dirinya. Inilah sesungguhnya tahap pertama di dalam belajar manusia.

Secara historis, konsep belajar sepanjang hayat tidak lepas dari proses pembangunan peradaban manusia. ${ }^{23}$ Perspektif belajar dari buaian sampai liang lahat (the cradle to grave ) dikenal luas dan dipromosikan di banyak negara. Seiring dengan berjalannya waktu dan kebutuhan belajar yang bervariasi, konsep dan bentuk belajar dan pendidikan menjadi lebih luas, sinergi dengan semangat dan kebutuhan untuk belajar secara terus menerus dalam berbagai kesempatan.

Dalam konteks saat ini, belajar sepanjang hayat dilihat sebagai proses yang mencakup tujuan (purposive) dan belajar lansung (directed learning). Setiap individu menyusun serangkaian tujuan belajar dan berupaya mencapainya dengan berbagai sumber di masyarakat. Orang yang berkomitmen terhadap belajar sepanjang hayat, akan memperoleh keuntungan penuh dari setiap kesemoatan belajar yang ada. Keuntungan tersebut dianataranya bahwa seseorang akan mampu menjadi seorang pembelajar yang mandiri (autonomous learners). Belajar sepanjang hayat, selanjutnya, mempomosikan kemandirian belajar diantara sesama anggota masyarakat sebagai parameter pembangunan sosial berkelanjutan.

Dalam perspektif Comission Communication of European Union ${ }^{24}$, belajar sepanjang hayat didefinisikan sebagai "'all learning activity undertaken throughout life, with the aim improving knowledge, skilss and competence, within a personal, civic, social and/or employment-related perspective". Aktivitas belajar sepanjang hayat berorientasi pada upaya pengembangan potensi manusia melalui proses yang mendukung secara terus menerus, yang menstimulusi dan memberdayakan individu-individu agar memperoleh semua pengetahuan, nilai-nilai, keterampilan-keterampilan dan pemahaman. Semuanya itu akan diperoleh dalam keseluruhan hidup individu dan kemudian menerapkannya dengan penuh percaya diri, penuh kreativitas, dan menyenangkan dalam seluruh peran, iklim, dan lingkungan. ${ }^{25}$

\footnotetext{
${ }^{22}$ Peter Jarvis, Globalication, Live Long Learning and the Learning Society: Sociological Perspektif, 2.

${ }^{23}$ Ehsanur Rahman, et. Al, Ganokendra People's Forum for Lifelong Learning and Social Development ( The Bangladesh Experience: Adult Education and Development Institut for Internasional Zusammnarbeit des Deutschen Volkschochschul-Verbandes, 2010), 23.

${ }^{24}$ Comission Communication, Making European Area of Lifelong Learning a Reality, Report Brussel, 2001, 673.

${ }^{25}$ Norman Longworth and W. Keith Davies, Lifelong Learning: Learning (London: Kogan page, 2006),
} 
Menurut Chen-Yen Wang belajar sepanjang hayat adalah "to learns as long as to live" (belajar sepanjang hidup), dan "learning has no boundaries" (belajar tanpa mengenal batas). Lebih lanjut Wang menyimpulkan bahwa belajar sepanjang hayat merupakan unsure "revolusi tenang" yang berimplikasi pada perubahan dalam berbagai aspek kehidupan seperti kehidupan politik, ekonomi, sosial, dan pendidikan. Terminologi lain yang dikemukakan Wang dan memilki konotasi yang smaa dengan belajar sepanjang hayat adalah "life-time learninh, life-wide learning, dan life-span learning". Budaya belajar sepanjang hayat amat flesksibel, kreatif dan responsive sehingga akan mampu memuaskan individu dan masyarakat dalam kehidupannya. ${ }^{26}$

\section{Konsep Mutu Pendidikan dan Kebijakan Mutu Pendidikan}

Penelitian yang dilaksanakan oleh Donald M. Morrison, Kelly Mohaski dan Katryn Kotter, yang hasilnya divalidasikan oleh the center for Reseach on Educational Policy of University of Memphis pada tahun 2005, menunjukkkan adanya sejumlah indicator kualitas pembelaaran (instructional quality indicators), yang dikelompokkan ke dalam 10 kategori, yaitu: (1) lingkungan fisik yang kaya dan merangsang, (2) iklim kelas yang kondiusif untuk belajar, (3) harapan jelas dan tinggi para peserta didik, (4) pembelajaran yang koheren dan berfokus, (5) wacana ilmiah yang meranssang pikiran, (6) belajar otentk, (7) asesmen diagnostic belajar yang teratur, (8) membaca dan menulis sebagai kegiatan regular, (9) pemikiran matematis, dan (10) penggunaan teknologi secara efektif. Kesepuluh kategori tersebut dijabarkan lagi menjadi 42 indikator. ${ }^{27}$

Konsep mutu pendidikan menurut Miarso mengandung lima rujukan, yaitu kesesuaian, daya tarik, efektivitas, efisiensi dan produktivitas. ${ }^{28}$ Ciri dari kesesuaian antara lain adalah sepadan dengan karakteristik peserta didik peorangan maupun kelompok, yaitu aspek-aspek atau kualitas seperti bakat, motivasi, dan kemampuan yang telah dimiliki oleh peserta-didik; (2) keserasian dengan aspirasi perseorangan maupun masyarakat; (3) kecocokan dengan kebutuhan masyarakat baik yang sifatnya normative, proyektif, ekspresif, maupun komparatif; (4) kesesuian dengan kondisi lingkungan, yang dapat meliputi budaya, sosial, politi, ekonomi, teknologi, dan wilayah; (5) keselarasan dengan tuntutan zaman yaitu misalnya untuk belajar lebih banyak, lebih cepat, dan terusmenerus sepanjang hayat; (6) ketepatan dengan teori, prinsip dan/atau nilai baru dalam bidang pendidikan, yaitu misalnya belajar menyelidik (inquiry learning), belajar memcahkan masalah belajar mandiri, belajar penguasaan, belajar struktur bidang studi dan lain sebagainya.

Pembelajaran yang bermutu juga harus mempunyai daya taik yang kuat, meliputi diantaranya: (1) sarana pendidikan yang tersebar dank arena itu mudah dicapai dan diikuti; (2) isi pendidikan yang mudah dicerna karena telah diolah sedemikian rupa; (3)

\footnotetext{
${ }^{26} \mathrm{CY}$. Wang, Advancing Lifelong Learning through Adult Education in Chinese Taipei, 2007, 56.

${ }^{27}$ D.M. Morrison, K. Mohaski \& K Cotter, Instrutional Quality Indicator Research Foundution $S$ (Cambridge, MA: Connect, 2005), 12.

${ }^{28}$ Yusufhadi Miarso, Menyemai Benih Teknologi Pendidikan (Jakarta: Pustekkom Diknas dan Kencana, 2004), 561.
} 
kesempatan yang tersedia yang dapat diperoleh siapa saja pada setiap saat diperlukan; (4) pesan yang diberikan kepada pada saat dan peristiwa yang tepat (just-in-time $=J I T$, bukan justin-case $=J I C=$ sekiranya diperlukan); (5) ketelandalan (accountability) yang tinggi, terutama karena kinerja (performance) lembaga dan lulusannya yang menonjol; (6) keanekaragaman sumber, baik yang sengaja dikembangkan maupun yang sudah tersedia dan dapat dipilih serta dimanfaatkan untuk kepentingan belajar; dan (7) suasana yang arab, hangat dan merangsang.

Efektivitas pembelajaran seringkali diukur dengan tercapainya tujuan, atau dapat pula diartikan sebagai ketetapan dalam mengelola suatu situasai (doing the night things). Pengertian ini mengandung ciri: (1) bersistem (sistematik), yaitu dilakukan secara teratur atau berurutan melalui tahap perencanaan, pengembangan, pelaksanaan, penilaian, dan penyempurnaan; (2) sensitive terhadap kebutuhan akan tugas belajar dan kebutuhan pembelajar; (3) kejelasan akan tujuan dank arena itu dapat dihimpun usaha untuk mencapainya; dan (4) bertolak dari kemampuan atau kekuatan mereka yang bersangkutan (peserta didik, pendidik, masyarakat dan pemerintah).

Menurut Deming sebagaimana dikutip Jenkis, pendidikan merupakan suatu system dengan tujuh komponen yang harus ada dan saling berkaiatan. ${ }^{29}$ Ke tujuh komponen tersebut adalah: (1) tujuan (aims); (2) pelanggan (customers); (3) persediaan (supplies); (4) masukan (input); (5) proses; (6) keluaran (output); dan (7) ukuran kualitas (quality measurement). Deming menyatakan bahwa tujuan umum pendidikan adalah meningkatkan hal-hal positif, mengurangi hal-hal yang negatif sehingga setiap peserta didik bergaira untuk belajar.

Salia $^{30}$ menyebukan bahwa setidak-tidaknya terdapat sebelas faktor yang dapat dijadikan acuan untuk mutu pendidikan, yaitu: (1) gedung yang terawatt baik; (2) guru yang bermutu; (3) nilai-nilai moral yang tinggi; (4) hasil ujian yang sangat baik; (5) spesialisasi program produk; (6) dukungan rang tua; (7) sumber belajar yang banyak; (8) penerapan teknologi yang mutakhir; (9) kepemimpinan yang kuat dan terarah; (10) kepedulian dan perhatian terhadap pserta didik; dan (11) kurikulum yang seimbang, atau beberapa kombinasi dari faktor-faktor tersebut,

\section{Kebijakan Belajar Sepanjang Hayat}

Komitmen UNESCO pada Forum Pendidikan Dunia di Dakar tahun 2000, adalah merumuskan pendekatan strategis agar upaya mencapai enam program utama EFA tersebut dapat direalisasikan sesuai targer sampai tahun 2015. Kerangka Aksi Dakar secara eksplisit mengakui bahwa pendidikan dari buaian dan pendidikan untuk anak-anak muda dan pendidikan berkelanjutan melalui belajar sepanjang hayat merupakan pusat pemberdayaan, untuk mengurangi kemiskinan dalam keluarga dan berbagai level kmunitas, serta untuk lebih memperluas pembangunan ekonomi dan sosial.

${ }^{29}$ L. Jenkis, Improving student Learning. Appliying Deming Quality Principles in Education (Milwauke, WI: ASOQ Pree. 2006), 12-13.

${ }^{30}$ E. Sallis, Total Quality Management in Education (London: Kogan Page, 2002$), 7$. 
Di dalam konteks ekonomi berbasis pengetahuan pada abad 21 ini, kesejahteraan, keamanan, perdamaian umat manusia, harmoni sosial dan keterpeliharaan lingkugan sangat bergantung pada akses dan kapasitas masyarakat untuk memilih, dan beradaptasi terhadap berbagaai peruabahan yang sangat cepat. Begitupula dengan keberlanjutan solusinya sehingga mampu menyikapi berbagai tantangan yang ada. Intinya, menghadapi semua situasi di atas, pendidikan dan belajar sepanjang hayat adalah kuncinya. ${ }^{31}$.

Strategi jangka menengah UNESCO (Medium-Term Strategy for 2008-2013), menegaskan bahwa pembangunan dan kesejahteraan ekonomi sangat bergantung pada kemampuan suatu Negara dalam mendidik warga negaranya. Belajar sepanjang hayat merupakan prinsip pengorganisasian yang penting untuk mencapai tujuan tersebut dan berkontribusi terhadap kemajuan belajar formal, nonformal, dan informal.

Di Indonesia belajar sepanjang hayat dalam konteks kebijakan pendidikan baru diposisikan sebagai daftar filosofis dan prinsip dalam nyelenggaraan pendidikan. hal tersebut terumuskan secara eksplisit dalam paying hukum yang langsung mengatur kebijakan pendidikan, yakni Undang-undang Nomor 20 Tahun 2003 tentang Sistem Pendidikan Nasional. Pasal-pasal yang menjelaskan secara langsung istilah pendidikan sepanjang hayat tercantum dalam Bab III tentang Prinsip Penyelenggaraan Pendidikan, Pasal 4, Ayat (3) yang menyebutkan bahwa "Pendidikan diselenggarakan sebagai suatu proses pembudayaan dan pemberdayaan peserta didik yang berlangsung sepanjang hyat". Bagian lain yang membahas tentang ini adalah Bab IV, Bagian Kesatu tentang Hak dan Kewajiban Warga Negara, pasal 5, Ayat (5) yang menjelaskan bahwa "Setiap warga Negara berhak mendapat kesempatan meningkatkan pendidikan sepanjang hayat".

Dalam konteks pendidikan nonformal, belajar sepanjang hayat merupakan visi Direktorat Jenderal Pendidikan Nonformal dan Informal (PNFI), sekarang (PAUDNI), yakni “Terwujudnya Manusia Indonesia Pembelajar Sepanjang Hayat". Selain sebagai visi, belajar sepanjang juga berfungsi sebagai pengganti, penambah, dan/atau pelengkap pendidikan formal dalam rangka mendukung pendidikan sepanjang hayat.

Sekedar perbandingan, di Jepang konsep belajar sepanjang diperkenalkan pada akhir tahun 1960-an. Kemudian tahun 1972, Faure Report dari UNESCO membenarkan konsep tersebut sebagai konsep yang relevan bagi masyarakat Jepang. Akan tetapi dalam perkembangannya muncul berbagai kritikan tajam terhadap konsep tersebut, karena dipandang memberikan tekanan terlalu keras terhadap pendidikan formal.

Dalam kaitannya dengan konsep di atas, Wilson berpendapat bahwa belajar sepanjang hayat sebagai garis hidup masyarakat Jepang saat ini. Pergeseran istilah dari pendidikan sepanjang hayat menjadi belajar sepanjang hayat menunjukkan adanya penekanan baru pada individu atau masyarakat sebagai self-directed agents dalam rangka pembelajaran mandiri. ${ }^{32}$

${ }^{31}$ J. Yang and R.F Cotera, Conceptual Evolution and Policy Development in Lifelong Learning (Hamburg: UNESCO Institut Lifelong Learning, 2011), viii.

${ }^{32}$ J.D. Wilson, Lifelong Learning In Japan: a Lifeline for Maturing Societ? Internasional Journal of lifelong Education Vol. 20 No. 4, July-August 2001, 297. 
Selain ini penggunaan kata "learning" atau belajar telah memecah peran monopoli Departemen Pendidikan dalam system pendidikan di Jepang dan memicu departemen lain untuk bekerjasama atau ikut serta dalam penyelenggaraan pendidikan yang yang terintegrasi. ${ }^{33}$ Oleh karenaa itu, tidak mengherankan apabila pemerintah jepang segera mewujudkan belajar sepanjang hayat sebagai undang-undang baru.

Pemerintah Jepang mensahkan Undang-undang Belajar Sepanjang Hayat tidak hanya sebaai konsep dasar biasa, namun dirancang agar dapat diimplementasikan secara konkrit. Atas alas an itulah, pada tahun 1992 dibentuk Badan Nasional Belajar Sepanjang Hayat yang bertugas memberikan saran bagi perkembangan kebijakan yang telah ditetapkan.

Undang-undang lifelong learning promotion memiliki tiga poin penting sebagai bentuk inovasi pendidikan, yaitu: (a) dukungan bagi tiap perfektur guna mendirikan Badan Belajar Sepanjang Hayat Perfektur serta merencanakan program belajar sepanjang hayatnya sendiri; (b) dukungan bagi lembaga bisnis swasta untuk bekerjasama dalam pengembangan masyarakat melalui program belajar sepanjang hayat terintegrasi dengan sektor-sektor publik dan pemerintah; dan (c) Departemen Perdagangan dan Perindustrian Internasional, birokrasi yang paling berpengaruh di Jepang, mempunyai rencana untuk ikut terlibat memfasilitasi industri belajar sepanjang hayat.

\section{Kompetensi Peserta Belajar Sepanjang Hayat}

Belajar sepanjang hayat memiliki dua sasaran utama yaitu; (1) sasaran individual, dan (2) sasaran komunal. Sasaran individual belajar sepanjag hayat berusaha menumbuhkembangkan manusia atau pembelajar (learning person), atau orang memiliki motivasi tinggi (motivating person). Sedangkan sasaran komunal dari belajar sepanjang hayat adalah masyarakat pembelajar (learning society) atau masyarakat perencana (planning society) atau masyarakat inovatif (innovative society).

Manusia pembelajar adalah manusai yang mendewasa yang dapat diartikan sebagai orang yang selalu berusaha mengembangkan potensi diri, mencapai prestasi terbaik dan kepuasan diri yang optimal dalam kehidupannya yang bermakna bagi dirinya sendiri dan bagi lingkungannya secara berkelanjutan. Knowless menjelaskan terdapat lima belas ciri dari sikap dan perilaku mendewasa yaitu: (1) mandiri; (2) aktif; (3) objektif; (4) memberikan tanggungjawab yang luas; (7) memiliki minat yang beragam; (8) memperhatikan orang lain; (9) memiliki integritas diri; (10) menerima kenyataan diri; (11) berpikir prinsip; (12) berpandangan mendalam; (13) gemar melakukan inovasi; (14) toleran terhadap perbedaan-perbedaan; dan (15) berpikir dan bertindak rasional. ${ }^{34}$

Menghadapi dinamika perkembangan jaman yang serba cepat dan kompleks diperlukan kesiapan setiap indvidu dan masyarakat untuk menjalaninya secara baik sesuai dengan situasi dan kondisi yang ada. Untuk menjadi seorang pembelajar sepanjang hayat

${ }^{33}$ J.E Thomas, et. All, New Lifelong Learning Law in Japan: Promise or Threat? International Journal of Lifelong Education Vol. 16 No. 2, Mach-April, 2000, 132.

${ }^{34}$ Malcolm S, Knowless, The Modern Practice Adult af Adult Education. Andragogy versus Pedagogy (New York: Association Press, 2003), h. 4. 
diperlukan sejumlah kemampuan dan keahlian tertentu sehingga individu dan masyarakat memiliki kesiapan untuk belajar apapun, dimanapun dan kapanpun menginginkannya. Seperangkat kemampuan dan keahlian tersebut selanjutnya terakumulasi dalam rumusan kompetensi.

International Board of Standars for Training, performance, and instruct-tion (IBSTPI), mendefiniskan kompetensi sebagai “...a knowledge, skill, or attitude that enables one to effectively perform the activities of a given occupation or function to the standars expected in employment." ${ }^{35}$ Kompetensi mencakup pengetahuan, sikap, dan keterampilan yang dipersyaratkan untuk melaksanakan tugas dan pekerjaan dalam jabatan tertentu. Sejalan dengan definisi IBSTPI, Muzaki ${ }^{36}$ mengartikan kompetensi (competency) sebagai keahlian (expertise) dan kewenangan (authority) seseorang untuk melakukan tugas atau pekerjaan dalam jabatan tertentu. Siskandar ${ }^{37}$ mengemukakan bahwa kompetensi adala pengetahuan, keterampilan dan nilai-nilai yang direfleksikan dalam kebiasaan berfikir dan bertindak. Selanjutnya mengindentifikasi enam pendekatan berbeda terhadap definisi kompetensi. Dapat dicatat bahwa kompetensi dipandang sebagai tugas pekerjaan, sebagai hasil usaha kerja, sebagai keluaran (output), sebagai pengetahuan, keterampilan sikap, sebagai mutu yang menjelaskan kinerja superior, dan terakhir sebagai perangkat atribut.

Kompetensi yang dikembangkan bagi peserta belajar adalah kompetensi kepribadian dan kompetensi sosial. Muzaki ${ }^{38}$, membahas kompetensi kepribadian sebagai kemampuan personal yang mencerminkan kepribadian yang mantap, stabil, dewasa, arif, dan berwibawa menjadi teladan bagi semua orang, serta berakhlak mulia. Sedangkan kompetensi sosiap berkenaan dengan kemampuan peserta belajar sebagai bagian dari masyarakat untuk berkomunikasi dan bergaul secara efektif dengan semua orang dan atau masyarakat sekitar.

Longworth dan Davies ${ }^{39}$ merinci sejumlah kecakapan (skills) yang harus disiapkan untuk memasuki era belajar sepanjang hayat. Kecakapan-kecakapan itu dirumuskan dan dikembangkan sesuai berdasarkan potensi manusia (human potential development). Memasuki era belajar sepanjang hayat dibutuhkan kompetensi dan kecakapan-kecakaan baru (new skills) yang didasarkan pada pengetahuan dan brain skills, yang menuntut kematangan mental dan kemampuan untuk memecahkan masalah. pengetahuan factual dan hard skills mencakup hanya sebagian kecil saja dari persyaratan belajar yang diminta. Pengalaman yang diperoleh individu selama hidupnya dapat menjelma menjadi kecakapan yang tak ternilai.

\footnotetext{
${ }^{35}$ Rita C. Richey, dkk. Instructional Design Competencies: The Standards (New York: ERIC Clearinghouse on Information and Technology Syracuse University, 2001), 31.

${ }^{36}$ Muzaki, et all. Analisis Kompetensi Tutor Pendidikan Kesetaraan Program Paket B di Provinsi Jawa Timur, Jurnal Ilmiah Visi, Vol. 3, No. 1, 2006, 6.

${ }^{37}$ Siskandar, Kurikulum Berbasis Kompetensi Pendidikan Dasar dan Menengah, makalah (Pusat Kurikulum Depdikanas: Jakarta, 2003), 12.

${ }^{38}$ Muzaki, et all. Analisis Kompetensi Tutor Pendidikan Kesetaraan Program Paket B di Provinsi Jawa Timur, 6.

${ }^{39}$ Norman Longworth and W. Keith Davies, Lifelong Learning: Learning, 62.
} 
Dalam perspektif Longworth dan Davies, paling tidak ada Sembilan kecakapan yang harus dimiliki seorang pembelajar sepanjang hayat, yaitu: (1) Belajar untuk belajar (Learning to learn); (2) menempatkan pengetahuan baru kedalam praktek; (3) mempertanyakan dengan alas an; (4) mengelola dirinya dan orang lain; (5) mengelola informasi; (6) Team work; (7) keterampilan memecahkan masalah; (8) Adaptabilitas dan fleksibilitas; dan (9) Memahami tanggung jawab dirinya untuk senantiasa memperbaharui dan meningkatkan kompetensinya.

Selanjutnya Evers, Rush, dan Berdrow ${ }^{40}$ mengelaborasi sejumlah kecakapan (skills) yang berorientasi pada kompetensi dasar, yaitu: (1) Memobilisasi Inovasi dan Perubahan (Mobilizing Innovation and Change), (2) Mengelola orang dan tugas pekerjaan (Managing People and Tasks), (3) Berkomunikasi (Coomunicating), dan (4) Mengelola Diri Sendiri (Managing Self).

\section{Proses Belajar Sepanjang Hayat}

Proses belajar dalam pendidikan sepanjang hayat dapat diartikan sebagai upaya seseorang, kelompok, atau suatu masyarakat dalam mencari, memperoleh, atau meningkatkan pengetahuan, keterampilan, sikap dan apresiasi yang dilakukan secara berkelanjutan di dalam kehiupan nyata guna meningkatkan kemampuan dan kepuasan diri sesuai dengan laju perubahan kehidupan yang semakin cepat. ${ }^{41}$

Belajar sepanjang hayat merupakan proses kontinum dari elemen-elemen yang saling berkaitan (interdependent), yang dilandasi oleh kebutuhan individu dalam pendidikan sepanjang hidupnya. Longworth dan Davies ${ }^{42}$ melukiskan proses belajar sepanjang hayat yang merentang dari pendidikan formal, nonformal hingga informal. Aksis A-pemelajar-adalah nilai, keterampilan, dan atribut belajar sepanjang hayat yang akan membawa pemelajar kea rah kemajuan melalui siklus belajar sepanjang waktu sebagai sebagaimana ditunjukkan dalam Aksis B. Aksis B adalah sepanjang hayat-tingkat perbedaan perjalanan hidup semua pemelajar ditempuh melalui perolehan pengetahuan dan pemahaman, melalui system belajar formal hingga system belajar informal. Aksis C adalah belajar merupakan seperangkat pendukung dari system belajar sepanjang hayat dimana pemelajar beradaptasi dengan kebutuhan belajarnya.

Tahapan-tahapan belajar dalam pendidikan sepanjang hayat dijalankan melalui program pendidikan. Tahapan-tahapan proses belajar dimaksud adalah:

1. Mengindentifikasi kebutuhan belajar yang dirasakan

2. Mendiskusikan tujuan yang ingin dicapai,

3. Menyusun rancangan program yang telah direncanakan,

4. Melakukan penilaian terhadap proses, hasil dan pengaruh dari program yang dilaksanakan.

${ }^{40}$ F.T. Evers, C. J. Rush dan I. Berdrow, The Bases Competence: Skills for Lifelong Learning and Employability (Ontario: Tigris Production, 2000), 40-41.

${ }^{41}$ H. Djudju Sudjana, Pendidikan Non Formal: Wawasan, Sejarah, Perkembangan, Filsafat, Teori Pendukung, Asas, 228.

${ }^{42}$ Norman Longworth and W. Keith Davies, Lifelong Learning: Learning, 19. 
Langkah-langkah sejenis dalam proses belajar sepanjang hayat tergambarkan dalam model self learning yang terdiri dari:

1. Mengamati orang lain yang sedang mengerjakan atau melakukan pekerjaa tertentu.

2. Membantu orang lain yang sedang membuat atau mengerjakan sesuatu pekerjaan tertentu.

3. Ikut serta dengan orang lain yang sedang bekerja membuat atau mengerjakan sesuatu pekerjaan tertentu.

4. Mengerjakan sendiri sesuatu pekerjaan yang menghasilkan sesuatu barang atau jasa tertentu.

5. Mengembangkan cara, model, dan produksi barang atau jasa tertentu sebagai hasil proses belajar yang diperoleh sebelumnya.

Proses belajar sepanjang hayat harus menempatkan nilai-nilai kecakapan hidup (life skills) sebagai muatan strategis yang terintegrasi dengan materi belajar sepanjag hayat.

Nilai kecakapan hidup dan kecakapan sosial dalam dunia belajar sepanjang hayat akan sangat baik bila dikembangkan melalui system kemitraan (partnership system) dengan melibatkan orangtua, gubernur, organisasi profesi, kelompok minat dan industri. Dalam gambar berikut terlihat ada sepuluh daftar kecakapan hidup paling atraktif bagi pengembangan wawasan dan nilai belajar sepanjang hayat.

Pentingnya belajar dari dan dalam dunia kehidupan nyata tidak terbatas pada upaya untuk memiliki dan meningkatkan pengetahuan, keterampilan, sikap, dan aspirasi saja. lebih jauh dari itu kegiatan belajar mencakup segi-segi kehidupan yang lebih luas seperti nilai keagamaan, hubungan sosial, adat istiadat, dan norma-norma yang berkembang dalam masyarakat. Kegiatan belajar diperlukan pula untuk menyesuaikan diri dengan perubahan positif yang terus berkembang dalam kehidupan. Dengan perkataan lain kegiatan belajar sepanjang hayat adalah untuk menyiapkan diri guna mencapai suatu kehidupan yang lebih baik di masa yang akan datang.

\section{Penjaminan Mutu Program Belajar Sepanjang Hayat}

Berkaitan dengan mutu belajar sepanjang hayat, Mead $^{43}$ dari SRI International, mengembangkan tujuh variable mutu pendidikan sepanjang hayat yang mengarah pada terjadinya pembelajaran yang efektif. Ketujuh variabel tersebut adalah sebagai beriku: (a) Pemelajar dilibatkan dalam tugas-tugas otentik dan multidisiplin; (b) Penilaian didasarkan atas performance of real tasks; (c) Pemelajar berpartisipasi secara aktif di dalam model-model pembelajaran yang interaktif; (d) Pemelajar bekerja secara kolaboratif; (e) Pemelajar dikelompokkan secara heterogen; (f) Instruktur adalah fasilitator dalam belajar dan pembelajaran; (g) Pemelajar belajar melalui eksplorasi.

Dimensi dan mutu semua variable di atas menggambarkan perlunya adanya keterllibatan pemelajar sehingga kompatibel dengan karakteristik pembelajar pada

${ }^{43}$ B. Mead, Practice Guide Assesing Lifelong Learning Technologhy (ALL-TECH): A Guide for Choosing and Using Technology for Adult Learning. NCAL Report, 2002, 5. 
program pendidikan sepanjang hayat. Di samping tujuah variable di atas, Mead menambahkan empat indicator baru yang dibutuhkan agar kerangka kerja pendidikan sepanjang hayat lebih mudah diterapkan sebagai berikut: (a) Transformatif; pemelajar diberdayaan dengan belajar dan mampu mendefinisikan keberadaan dirinya dalam tujuan bersama;(b) membangun pengalaman hidup; tugas-tugas belajar didasarkan pada pengalaman hidup pemelajar; (c) pemberian penghargaan; pengetahuan dan keterampilan diperlukan dalam tugas belajar yang memberikan keuntungan langsung terhadap pemelajar; dan (d) mengakomodasi perbedaan-perbedaan belajar; pembelajaran dirangsang berdasarkan model-model yang ada dan memungkinkan diterapkan, sehingga menagarah pada gaya dan preferensi belajar.

Dalam deskripsi yang lebih jelas, European Comission $^{44}$ yang merupakan perwakilan dari 35 negara Eropa, telah mengadakan pengkajian tahun 2002 mengenai indicator mutu belajar sepanjang hayat. Indicator-indikator tersebut memiliki perang penting dan trategis dalam pendidikan sepanjang hayat, yaitu (a) to describe the present situation, (b) to quantify the objectives which have been set, (c) to provide continuous updates on progress towards certain objectives or, (d) to provide insights into which factors might have contributed to achieving results.

Laporan komisi tersebut menyatakan adanya 15 indikator mutu belajar sepanjang hayat yang dapat dikelompokkan dalam empat kategori. Kategori dan indikator tersebut adalah:

Area A:Skills, competencies and attitudes

1. Literacy

2. Numeracy

3. New Skills in the Learning society

4. Learning-to-Learn Skills

5. Active Citenship Cultural and Social Skills

Areal B: Acces and Participation

6. Access to Lifelong Learning

7. Participation in Lifelong Learning

Area C: resources for Lifelong Learning

8. Investment in Lifelong Learning

9. Educators and Training

10. ICT in Learning

Area D: Strategies and system Development

11. Strategies of Lifelong Learning

12. Coherence of Supply

13. Counseling and Guidance

14. Accredatitation and Certification

15. Quality Assurance

${ }^{44}$ Comission Communication, Making European Area of Lifelong Learning a Reality, Report Brussel, 2001, 
Mansell dan Uta When dalam laporannya untuk United Natoins Comission on Science and Technology Development (UNSCTD) bahwa ada lima isu utama yang perlu diperhatikan untuk terbentuknya masyarakat berpengetahuan (knowledge society). Masyarakat berpengetahuan dan keterampilan yang diperlukan, serta memperoleh akses informasi. Kelima isu tersebut adalah : (1) Kebijakan dan Peraturan Perundangan, (2) Akses terhadap Informasi, (3) Partisipasi dalam Proses Pembangunan, (4) Pengetahuan dan Keterampilan Dasar, dan (5) Sarana Teknologi Informasi dan Komunikasi.

Europian Comission ${ }^{45}$ menegaskan bahwa penjaminan mutu merupakan bagian penting dari suatu system dan pelatihan yang efektif. Upaya penjaminan mutu tidak mudah dilakukan karena memerlukan dukungan berbagai instrument, seperti kebijakan, adanya mekanisme yang jelas, adanya seperangkat instru,en yang mampu mengukur bermutu atau tidaknya suatu program belajar sepanjang hayat.

Permendiknas RI Nomor 30 tahun 2005 Pasal 1 Ayat (1) dan (2) menyebutkan bahwa Badan Akreditasi Nasional Pendidikan Non Formal yang selanjutnya disebut BAN-PNF adalah badan evaluasi mandiri yang menetapkan kelayakan program dan/atau satuan pendidikan jalur pendidikan non formal dengan mengacu pada standar nasional pendidikan.

Akreditasi pendidikan nonformal adalah suatu kegiatan penilaian kelayakan suatu satuan pendidikan nonformal berdasarkan criteria yang telah ditetapkan dan dilakukan oleh BAN-PNF yang hasilnya diwujudkna dalam bentuk pengakuan peringkat kelayakan.

Selain hal di atas, upaya penjaminan mutu juga dapat dilakukan melalui penilaian program belajar sepanjang hayat yang berstandar. System penilaian yang ada saat ini tidak didasarkan pada model penilaian potensi manusia belajar sepanjang hayat (lifelong leraning human potential model) melainkan sebaliknya. ${ }^{46}$ Penilaian didasarkan pada divisi dan lebih berorientasi pada upaya mendorong kelulusan dan mengeliminasi kegagalan, jadilah penilaian identik dengan sejumlah pertanyaan, sehingga peserta belajar berada dalam posisi sebagai seubjek pertanyaan. Ditegaskan Longworth dan Davies, belajar sepanjang hayat sedang berupaya mengubah paradigm ujian dengan menciptakan strategi penilaian yang lebih fleksibel.

Pengakuan dan penilaian terhadap hasil sebelumnya atau saat ini lebih dikenal sebagai PLAR (Prior Learning Assesment and Recognation), merupakan sebuah proses yang membantu orang dewasa belajar bahwa mereka memperoleh pendidikan di luar pengaturan atau system yang ada. Banyak individu orang dewasa yang memiliki hasil belajar setingkat diploma, kecakapan melalui pekerjaan yang bervariasi, dan pengalaman hidup.

Penilaian PLAR dilakukan dengan berbasis pada individu. Focus penilaian ini adalah pada apa yang orang dewasa ketahui dan dapat dilakukan. PLAR digunakan untuk menilai pengetahuan dan keterampilan seseorang dalam kaitannya dengan criteria tertentu. Pendirian yang jelas dan terukur merupakan criteria kunci berkualitas tinggi 68.

${ }^{45}$ Comission Communication, Making European Area of Lifelong Learning a Reality, Report Brussel, 2001,

${ }^{46}$ Norman Longworth and W. Keith Davies, Lifelong Learning: Learning, 109. 
PLAR. Laporan Manitoba University (2003-2005), menegaskan bahwa Prior Learning Assessmentand Recognition (PLAR) merupakan metode yang digunakan untuk mengindentifikasi, mendokumentasi, menilai, dan mengakui kecakapan (skills) dan pengetahuan (knowledge). PLAR merupakan instrument vital di dalam mendorong terjadinya proses belajar secara terus menerus dan mengembangkan kecakapan seseorang agar agar lebih mumpuni. Selain itu PLAR juga membantu seseorang berhak memperoleh pengakuan terhadap apa yang mereka tahu dan lakukan baik di ruang kelas, tempat kerja, dan di masyarakat.

Khusus bagi pembelajar orang dewasa yang melakukan proses belajar mandiri, menurut Percy. ${ }^{47}$ Model yang dikembangkan harus mereflesikan pengalaman, karir professional, aktivitas social di masyarakat, penghargaan dan sertifikat, kunjungan kerja, menjadi nara sumber, permintaan untuk menjadi penasehat dan lain-lain.

Berbagai metode dapat digunakan untuk menilai hasil belajar sebelumnya, diantaranya demonstrasi, wawancara terstruktur, dan presentasi contoh-contoh atau produk tertentu. Beberapa organisasi profesi menawarkan kursus pengembangan portifolio. Portifolio merupakan sebuah koleksi dokumen terorganisir dan item lainnya yang menunjukkan apa yang individu ketahui dan bisa lakukan. Sebagai catatan, bahwa PLAR tidak mengakui pengalaman, namun mengakui pengetahuan dan keterampilan yang telah diperoleh seseorang dari pengalaman mereka. PLAR merupakan perpaduan strategi asesmen untuk mengevaluasi keluasan dan kedalaman belajar seseorang. Metode tersebut mencakup metode tradisional seperti ujian tertulis, wawancara, demonstrasi dan ujian lisan. Adapun alat penilaian lain yang digunakan adalah portofolio belajar yang mencakup berbagai hasil belajar yang diperoleh sebelumnya melalui pekerjaan, kursus, pengalaman berorganisasi, dan kecakapan lainnya yang divalidasi dengan bukti-bukti sertifikat.

PLAR memberikan beberapa keuntungan bagi penggunanya (user), khususnya peserta belajar yang dewasa, yaitu:

1. Mengakselerasikan penyelesaian suatu program, belajar.

2. Menghemat dan menjembatani keterbatasan financial

3. Meningkatkan kepercayaan diri dan harga diri (self-esteem) karena ada pengakuan terhadap pengalaman dan prestasi sebelumnya.

4. Memperkuat jarringan antara hasil studi formal, pekerjaan dan pengalaman hidup seseorang.

Pengakuan pengalaman belajar melalui proses artikulasi dan transfer. Sebagaimana dikemukakan Kintzer $^{48}$ bahwa hasil belajar tidak terbatasi oleh tempat dan waktu kegiatan belajar dilaksanakan. Di samping itu pengakuan terhadapa pengalaman belajar

\footnotetext{
${ }^{47}$ Keith Percy, On Formal, Non-Formal and Informal Lifelong Learning: Reconceptualising the boundaries for research, Theory and Practice. Research in the Education of Adults, 27th Annual SCUTREA Conference Proceedings, 2001.

${ }^{48}$ F.C. Kintzer, Artculation and Transfer. Critical Cintribution to Lifelong Learning. Lifelong Learning: Policies, Practice and Programs, ed. Michael j. Hatton, Toronto: School of Media Studies at Humburg College, 2007, 70.
} 
akan dapat meningkatkan harga diri dan kepercayaan diri, meningkatkan efisiensi dan efektifitas proses belajar.

Pemahaman artikulasi dan transfer dalam konteks pendidikan sepanjang hayat, jenis-jenis artikulasi dan implementasinya serta kemungkinannya di masa depan, relevan dibahas dalam penelitian ini. Mengingat kecenderungan kebijakan yang ada saat ini di Indonesia sedang menuju ke arah itu, seiring dengan digulirkannya konsep Pengakuan Pengalaman Kerja dan Hasil Belajar (Permendiknas No. 58 Taun 2008 tentang Penyelenggaraan Program Sarjana (S-1) Kependidikan bagi guru dalam jabatan. Artikulasi adalah totalitas proses dan hubungan menyangkut perpindahan sistematis peserta didik baik vertical maupun horizontal melalui pendidikan formal maupun non formal. Sedangkan transfer diartikan sebagai pertukaran kurikulum, kredit atau mata kuliah. Termasuk didalamnya adalah pengakuan kredit yang diperoleh dari pengalaman belajar informal, yang secara khusus dimaksudkan untuk memperoleh kredit. Dalam kontek pendidikan sepanjang hayat artikulasi ini mempunyai peranan penting. Pengalaman belajar yang diperoleh sepanjang haya dapat diaui sebagai kredit yang dapat digunakan untuk melanjutkan ke perguruan tinggi.

Proses pengakuan kredit, tidak hanya dilakukan pada kredit yang diperoleh melalui pendidikan formal, tetapi juga terhadap pengalaman belajar yang diperoleh seseorang (experiential learning). Lembaga yang pertama kali melakukan ini adalah State University of New York (SUNY), dengan nama College Preficiency Examination Program (CPEP). Dalam system ini, pengakuan kredit dilakukan melalui evaluasi. Ada dua tipe evaluasi yang dilakukan, yaitu ujian dan penghargaan. Itulah selama ini cara pertama yang paling banyak dilakukan. Evaluasi yang dilakukan melalui wawancara dan portofolio. Pengakuan pengalaman belajar ini kemudian menjadi perhatian secara nasional, yaitu dengan dibentuknya komisi College Extrance Examination Board and Educational Testing Service. Komisi ini bertugas mengembangkan konsep, prinsip dan pedoman yang dapat digunakan secara local, yang dikenal dengan proyeknya Cooperative Assesment of Experential Learning (CAEL).

\section{Penutup}

Konseptualisasi belajar sepanjang hayat dalam kebijakan pendidikan hanya sebagai perinsip penyelenggara. Kebijakan khusus yang mengatur tentang itu di Indonesia belum ada. Terdapat empat aspek yang penting kontribusinya dalam menentukan rumusan belajar sepanjang hayat, yaitu aspek kebijakan BSH, kompetensi peserta belajar, proses belajar dan upaya penjaminan mutu. Implementasi kebijakan belajar sepanjang hayat di Indonesia harus mempertimbangkan tiga tujuan strategik yaitu: peningkatan kualitas dan efektivitas sistem pendidikan dan pelatihan, memfasilitasi semua akses sistem pendidikan dan pelatihan dan membuka sistem pendidikan dan pelatihan yang lebih luas.

Proses belajar sepanjang hayat harus mendorong tumbuhnya kompetisi yang sehat dalam menunjukkan sumber-sumber belajar alternatif di masyarakat. Mengembangkan 
pola belajar mandiri, individu maupun kelompok yang bersumber dari minat dan kebutuhan belajar masyarakat, menggunakan metode yang bervariasi dalam setiap aktivitas pembelajaran yang disesuaikan dengan tujuan pembelajaran, dan menggunakan media teknologi informasi dan komunikasi yang tersedia di masyarakat. Melalui program pengawasan yang sistematis, sertifikasi tenaga pendidik dan kependidikan , akredirtasi satuan/ program $\mathrm{BSH}$, dan penilaian program belajar sepanjang hayat yang terstandar dengan terus mengembangkan pola pengakuan dan penilaian terhadap hasil sebelumnya atau PLAR (Prior Learning Assesment and Recognation), sistem artikulasi (pindah jalur secara horisontal dan vertikal) dan tranfer (konversi atau kredit).

\section{Daftar Pustaka}

Abdi, Ali A and Dip. Kapoor, Global Perspektif on Adult Education, New York: Palgrave MacMilan, 2009.

Aspin, David N and Judith D Chapman (ed), Values Education and Lifelong Learning: Principles, Polices, Programmes. Dordrecht, the Netherlands: Springer, 2007.

Comission Communication, Making European Area of Lifelong Learning a Reality, Report Brussel, 2001.

Drucker, Peter F. Knowledge Work and Knowledge Society: the Social Transformation of this Century http://www.knowledge.org, 2004

------. Manajemen di Tengah Perubahan, Jakarta: Gramedia, 2007.

Evers, F.T., C. J. Rush dan I. Berdrow. The Bases Competence: Skills for Lifelong Learning and Employability, Ontario: Tigris Production, 2000.

Gani, Lilik. Belajar dengan Teknologi Menunju Masyarakat Berpengetahuan, Makalah Kongres VI dan Seminar Nasional Ikatan Profesi Pendidikan Teknologi Pendidikan (IPTPI).

Hargreaves, Andy. Teaching in the Knowledge Society: Education in the Age of Insecurity, New York and London: Columbia University, 2003.

Hatton, J. Michael. Lifelong Learning: Policies, Practice and Programs, Toronto: School of Media Studies at Hamburg College, 2007.

Jarvis, Peter. Globalication, Live Long Learning and the Learning Society: Sociological Perspektif, London and New York: Routledge, 2007.

Jenkis, L. Improving student Learning. Appliying Deming Quality Principles in Education, Milwauke, WI: ASOQ Pree. 2006.

Kementerian Agama RI, Syaamil al-Qur'an Terjemah Tafsir Per Kata, Bandung: PT. Sygma Examedia Arkaleema, 2014.

Kintzer, F.C. Artculation and Transfer. Critical Cintribution to Lifelong Learning. Lifelong Learning: Policies, Practice and Programs, ed. Michael j. Hatton, Toronto: School of Media Studies at Humburg College, 2007.

Knowless, Malcolm S. The Modern Practice Adult af Adult Education. Andragogy versus Pedagogy New York: Association Press, 2003. 
Longworth, Norman and W. Keith Davies. Lifelong Learning: Learning, London: Kogan page, 2006.

Lyoratrd J.F. The Post Modern Condition: a Report on Knowledge Manchester, Manchester University Press, 2004.

Mead, B. Practice Guide Assesing Lifelong Learning Technologhy (ALL-TECH): A Guide for Choosing and Using Technology for Adult Learning. NCAL Report, 2002.

Miarso, Yusufhadi. Menyemai Benih Teknologi Pendidikan, Jakarta: Pustekkom Diknas dan Kencana, 2004.

Morrison D.M., K. Mohaski \& K Cotter. Instrutional Quality Indicator Research Foundution, Cambridge, MA: Connect, 2005.

Muzaki, et all. Analisis Kompetensi Tutor Pendidikan Kesetaraan Program Paket B di Provinsi Jawa Timur, Jurnal Ilmiah Visi, Vol. 3, No. 1, 2006.

Percy, Keith. On Formal, Non-Formal and Informal Lifelong Learning: Reconceptualising the boundaries for research, Theory and Practice. Research in the Education of Adults, 27th Annual SCUTREA Conference Proceedings, 2001.

al-Quzwaini, Ibn Ma>jah Abu> 'Abdillah Muh\}ammad bin Yazi $>>d$, Sunan Ibn $M a>j a h$, Juz I, Mauqi' al-Islam: t.tp, t.th

Rahman, Ehsanur, et al, Ganokendra People's Forum for Lifelong Learning and Social Development, The Bangladesh Experience: Adult Education and Development Institut for Internasional Zusammnarbeit des Deutschen VolkschochschulVerbandes, 2010.

Richey, Rita C., dkk. Instructional Design Competencies: The Standards, New York: ERIC Clearinghouse on Information and Technology Syracuse University, 2001.

Rogers, Alan. Non-Formal Education: Fleksibel Schooling or Participatory Education?, New York: Springger Science Bussines Medis Inc, 2005.

Sallis, E. Total Quality Management in Education, London: Kogan Page, 2002.

Setiadi B. Membangun Indonesia Knowledge Based Society, Jakarta: Kementerian Riset Teknologi Bidang Program Ilmu Pengetahuan dan Teknologi, 2007.

Siskandar, Kurikulum Berbasis Kompetensi Pendidikan Dasar dan Menengah, makalah, Pusat Kurikulum Depdikanas: Jakarta, 2003.

Sudjana, H. Djudju, Pendidikan Non Formal: Wawasan, Sejarah, Perkembangan, Filsafat, Teori Pendukung, Asas, Bandung, Falah Pruduction, 2004.

Thomas, J.E, et. all. New Lifelong Learning Law in Japan: Promise or Threat? International Journal of Lifelong Education Vol. 16 No. 2, Mach-April, 2000.

UNESCO. Global Report on Adults Learning ang Education, Hamburg: UNESCO Institut for Lifelong Learning, 2009.

------. to Wards Knowledge Societies, Paris: UNESCO, 2005.

Wang, CY. Advancing Lifelong Learning through Adult Education in Chinese Taipei, 2007.

Wilson, J.D. Lifelong Learning In Japan: a Lifeline for Maturing Societ? Internasional Journal of lifelong Education Vol. 20 No. 4, July-August 2001. 
Yang, J. and R.F Cotera. Conceptual Evolution and Policy Development in Lifelong Learning, Hamburg: UNESCO Institut Lifelong Learning, 2011. 